\title{
Bio-Ethanol Production from Banana, Plantain and Pineapple Peels by Simultaneous Saccharification and Fermentation Process
}

\author{
J. Itelima, F. Onwuliri, E. Onwuliri, Isaac Onyimba, and S. Oforji
}

\begin{abstract}
Most nations, whether economically advanced or at different stages of development are faced with the problem of disposal and treatment of wastes. Wastes could be treated in several ways (e.g. by reducing its bulk or by recovering and reprocessing it into useful substance) to meet sanitary standards. Ethanol fermented from renewable sources for fuel or fuel additives are known as bio-ethanol. In Nigeria, many food crops have been specifically grown for the production of bio-ethanol. However, bio-ethanol production from waste materials removed from fruits is very rare. In the present study, wastes from fruits such as banana, plantain and pineapple peels which are in abundance and do not interfere with food security were subjected to simultaneous saccharification and fermentation for 7days by co-culture of Aspergillus niger and Saccharomyces cerevisiae. Biomass yield, cell dry weight, reducing sugar concentration and the ethanol yield were determined at 24 hours interval. The results of the study showed that after 7 days of fermentation, pineapple peels had the highest biomass yield of 1.89 (OD), followed by banana peels 1.60 (OD), while plantain peels had the least 0.98 (OD). The reducing sugar concentrations ranged between $0.27-0.94 \mathrm{mg} / \mathrm{cm}^{3}$ for pineapple, $0.20-0.82 \mathrm{mg} / \mathrm{cm}^{3}$ for banana and $0.16-0.45$ $\mathrm{mg} / \mathrm{cm}^{3}$ The optimal ethanol yields were $8.34 \% \mathrm{v} / \mathrm{v}, 7.45 \% \mathrm{v} / \mathrm{v}$ and $3.98 \% \mathrm{v} / \mathrm{v}$ for pineapple, banana and plantain peels respectively. These indicate that pineapple and banana peels ethanol yields were significantly higher $(\mathbf{P}<0.05)$ than plantain peel ethanol yield. The findings of this study suggest that wastes from fruits that contain fermentable sugars can no longer be discarded into our environment, but should be converted to useful products like bio-ethanol that can serve as alternative energy source.
\end{abstract}

Index Terms-Bio-ethanol, banana, plantain, pineapple, peels.

\section{INTRODUCTION}

The conversion of corn and other food feed crops into ethanol by fermentation is a well- known and established technology. The United States and other countries desperately need a liquid fuel replacement for fossil oil in the future. The use of oil was projected to peak about 2007 and the supply is then projected to be extremely limited in 40-50 years [1]. Alternative liquid fuels from various sources have been sought for many years and since the cost of raw materials which can account up to $50 \%$ of the total

Manuscript received December 5, 2012; revised February 5, 2013.

J. Itelima and F. Onwuliri are with the Department of Plant Science and Technology.

E. Onwuliri is with the Department of Pharmaceutical Microbiology all of University of Jos Nigeria.

A. Onyimba and S. Oforji are with the University of Jos, Nigeria (e-mail: janetitelima@yahoo.com). production cost is one of the most significant factors affecting the economy of alcohol, nowadays efforts are more concentrated on using cheap and abundant raw materials [2]. Several forms of biomass resources exist (starch or sugar crops, weeds, oils plants, agricultural, forestry and municipal wastes) but of all biomass cellulosic resources represent the most abundant global source [3]-[6].

No other sustainable option for production of transportation fuels can match ethanol made from lignocelluloses biomass with respect to its dramatic environmental, economic and infrastructure advantages. The lignocellulosic materials include agricultural residues, municipal solid wastes (MSW), pulp mill refuse, switch grass and lawn, garden wastes [1].

Currently there is a growing interest for ecological sustainable bio-fuels all over the world. In Nigeria, simultaneous saccharification and fermentation of lignocelluloses to alcohol by Baker's yeast and a thermorolerant $K$. marxianus using wastes as substrate was reported by [3], while simultaneous saccharification and fermentation of yam peel to ethanol by co-culture of Aspergillus niger and Saccharomyces cerevisiae was reported by [7]. Saccharomyces cerevisiae is also widespread in their distribution. They are frequently found growing saprophytically on fruits, sugary exudates of trees nectar of flowers and other substrates that contain sugar. They also grow on grains decaying vegetables and in soil containing abundant of humus in decaying organic matter and milk products [8]. The species of $S$. cerevisiae commonly known as Baker's yeast is the most important representative of the genus Saccharomyces. Brewer's yeast, wine yeast and distiller's yeast are also varieties of S. cerevisiae [9]. Among other uses, yeasts have the ability to ferment a sugar solution poorly supplied with oxygen, resulting in the formation of alcohol and carbondioxide. The spores of A. niger are widespread and are often associated with organic materials and soil [8]. The primary uses of A. niger are for the production of enzymes and organic acid by fermentation processes. A. niger produces enzymes such as amylase, amyloglucosidase, cellulases, lactase, invertase and pectinases [10].

Although ethanol is both solvent and fundamental feed stock for the synthesis of other products, it also a safer alternative to methyl tertiary butyl ether (MTBE), the most common addition to gasoline use to provide cleaner combustion [7]. The United States Environmental protection Agency (EPA) announced the beginning of regulatory action to eliminate MTBE in gasoline because it is a toxic chemical compound and has been found to contaminate group water 
[11]. Hence, the demand for ethanol could increase further if MTBE is eliminated from gasoline. The objective of this study was to produce ethanol from wastes such as banana, plantain and pineapple peels which are abundant and do not interfere with food security using co-culture of Aspergillus niger and Saccharomyces cerevisiae.

\section{MATERIALS AND METHODS}

\section{A. Preparation of Banana, Plantain and Pineapple Peels for Ethanol Production}

Ripped Banana, plantain and pineapple obtained from the market in Jos Plateau State, Nigeria were washed, and their outer coats i.e. removed, cut in small pieces using a knife and then blended with sterile distilled water in ration of $1: 10$ respectively using electric blender and stored in refrigerator prior to use.

\section{B. Preparation of Growth Medium}

The growth medium used for preparing the Aspergillus niger inoculum (obtained from garden soil) consisted of $30 \mathrm{~g}$ of the blended banana, plantain and pineapple peels (substrates ), peptone, $0.1 \%$; malt extract, $0.1 \%(\mathrm{w} / \mathrm{v})$, yeast extract, $0.2 \%(\mathrm{w} / \mathrm{v})$, calcium carbonate $0.2 \% \quad(\mathrm{w} / \mathrm{v})$; ammonium phosphate, $0.2 \% \quad(\mathrm{w} / \mathrm{v})$, and ferrous sulphate. $7 \mathrm{H}_{2} \mathrm{O}, \quad 0.001 \% \quad(\mathrm{w} / \mathrm{v})$ and respectively. Saccharomyces cerevisiae (obtained from ripped banana peels) growth medium was prepared using yeast - malt broth at $\mathrm{pH} 5.5$ [12].

\section{Preparation of Inocula and Fermentation Procedure}

A. niger inoculum was prepared in $250 \mathrm{~cm}^{3}$ cotton-plugged conical flask containing $100 \mathrm{~cm}^{3}$ of the different substrates growth media. The flasks were sterilized and inoculated with 0.11 (OD) A. niger spores. Each of the flasks was incubated on a shaker with agitation rate of $300 \mathrm{rpm}$ at $30^{\circ} \mathrm{C}$ for five days. S. cerevisiae inoculum was prepared in the same way as the $A$. niger inoculum except that yeast malt broth was used. The growth medium was inoculated with 0.08 (OD) yeast cells and incubated for 24 hours. The fermentation medium used for ethanol production was identical to the growth medium as indicated above. Ethanol fermentation was carried out in $1000 \mathrm{~cm}^{3}$ conical flasks each containing $300 \mathrm{~cm}^{3}$ of medium. The medium was sterilized and inoculated with $5 \%(\mathrm{v} / \mathrm{v})$ growth media containing A. niger and S. cerevisiae and incubated on a shaker with an agitation rate of 300rpm at $30^{0} \mathrm{C}$ for seven days.

\section{Analytical Procedure}

Thirty cubic centimeters $\left(30 \mathrm{~cm}^{3)}\right.$ of the sample was collected from each flask at 24 hours interval and $27 \mathrm{~cm}^{3}$ was centrifuged at $400 \mathrm{rpm}$ for 30 minutes to remove the cells. The supernatant fluid was filtered through Whatman filter paper No.1 and the filtrate was used for determining ethanol and reducing sugar concentration. The remaining $3 \mathrm{~cm}^{3}$ was used to determine the cell density.

\section{E. Determination of Cell Density}

Three cubic centimeters $\left(3 \mathrm{~cm}^{3}\right)$ of the sample was used to determine the cell density at 690nm using CECILCE 1020 spectrophotometer. The spectrophotometer was blanked with an uninoculated fermentation medium.

\section{F. Quantitative Analysis of Reducing Sugar Present in the Samples}

The quantitative analysis was carried out using 3,5-dinitrosalicylic acid. The concentration of the reducing sugar present in the samples was determined by adding $1 \mathrm{~cm}^{3}$ of 3,5-dinitrosalicylic acid to $1 \mathrm{~cm}^{3}$ of each of the samples and boiled for 5 minutes and $10 \mathrm{~cm}^{3}$ distilled water was added. The absorbance of each of sample was determined at 540nm using JENWAY 6400 spectrophotometer. Thus, the concentration values were extrapolated from the glucose standard curve [13].

\section{G. Qualitative and Quantitative Analysis of Ethanol Present in the Distillate}

The filtrates were distilled at $70^{\circ} \mathrm{C}$ using rotary evaporator. The qualitative analysis was carried out using ethanolic acid. Two cubic centimeters of ethanolic acid was added to $1 \mathrm{~cm}^{3}$ of the distillate and heated in the water bath for 5 minutes until characteristics sweet smell of esters was perceived. The quantitative analysis was carried out by determining the densities of the distillates as follows.

$$
\begin{gathered}
\text { Density }=\frac{W B+D-W E B}{V D} \\
W B=\text { Weight of the Density Bottle } \\
D=\text { Distillate } \\
W E B=\text { Weight of Empty Density Bottle } \\
V D=\text { Volume of Distillate }
\end{gathered}
$$

Thus, concentrations of the distillates were extrapolated from the density standard curve. Furthermore, the $\mathrm{pH}$, refractive index, and specific gravity values were extrapolated from the standard curves prepared from each parameter since the concentrations of the distillates were known [13].

\section{RESULTS AND DISCUSSION}

The yeast and mould (biomass) yield was obtained by determining the absorbance of the samples at $690 \mathrm{~nm}$ which represented the cell density (Table 1). The results show that from the first day to the seventh day of fermentation, the yeast and mould biomass yield obtained from pineapple, banana and plantain peels fermentation media increased from 0.34 to 1.89 (OD), 0.28 to 1.60 (OD) and 0.21 to 0.98 (OD) respectively. The ability of the amylase and cellulase secreted by $A$. niger to breakdown the 3 substrates into reducing sugar was determined in the study. The results are presented in Fig. 1 in terms of the amount of reducing sugars $(\mathrm{mg} / \mathrm{cm} 3)$ produced at 24 hours interval for seven days. The results show that in all the substrates the concentration of the reducing decreased gradually as the fermentation period increased. Thus, on day 7 of the fermentation period, the highest reducing concentration $\left(0.94 \mathrm{mg} / \mathrm{cm}^{3}\right)$ was obtained from pineapple peel. This was closely followed by banana 
peel $\left(0.82 \mathrm{mg} / \mathrm{cm}^{3}\right)$ while plantain peel had the least $\left(0.45 \mathrm{mg} / \mathrm{cm}^{3}\right)$.

TABLE I: YeAST AND MOULD BIOMASS Yield OBTAINED FROM BANANA, Plantain AND PineapPle PeEls Fermentation MEDIUM For SEVEN DAYS

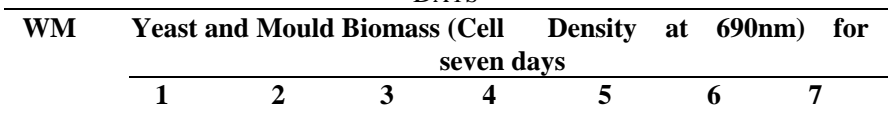

$\begin{array}{llllllll}\text { BP } & 0.28 & 0.62 & 0.93 & 1.05 & 1.30 & 1.52 & 1.60 \\ \text { PP } & 0.21 & 0.37 & 0.51 & 0.85 & 0.89 & 0.92 & 0.98 \\ \text { PIP } & 0.34 & 0.85 & 1.22 & 1.45 & 1.63 & 1.78 & 1.89\end{array}$

$W M=$ Waste Material, $B P=$ Banana Peel, $P P=$ Plantain Peel, $P I P=$ Pineapple Peel

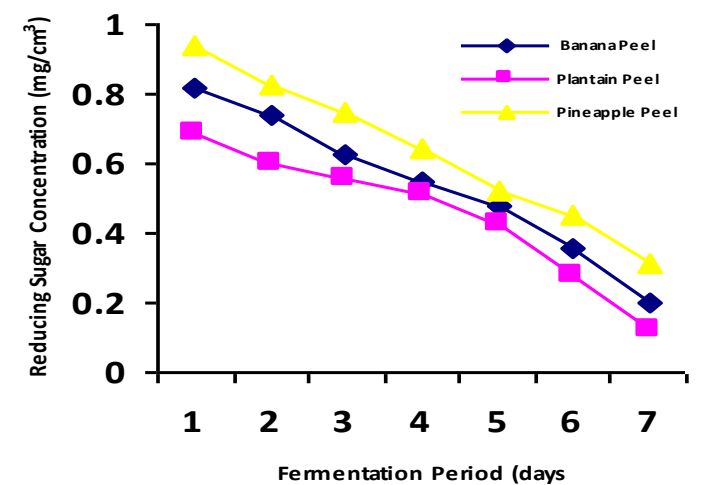

Fig. 1. Reducing sugar concentrations obtained from banana, plantain and pineapple peels fermentation medium for seven days.

The results of the ethanol yield obtained from the three substrates are shown in Figure 2. During the fermentation period, the ethanol yield of the 3 substrates were found to increase gradually from the first day to the seventh day with the pineapple peel having the highest yield of $8.34 \%(\mathrm{v} / \mathrm{v})$, followed by banana peel $7.45 \%(\mathrm{v} / \mathrm{v})$, while the least was obtained from plantain peel $3.98 \%(\mathrm{v} / \mathrm{v})$. The ethanol yield from pineapple in this study compared favourable with the ethanol yield obtained by [7]. These authors reported that they obtained $9.30 \%(\mathrm{v} / \mathrm{v})$ after 7 days of fermentation period.

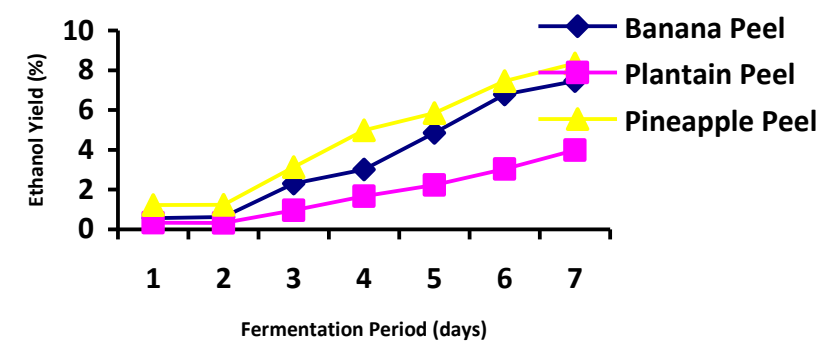

Fig. 2. Ethanol yield obtained from banana, plantain and pineapple peels fermentation medium for seven days.

Agricultural wastes rich in fermentable sugars have been found to be good substrates for ethanol production, a promising alternative energy source for limited crude oil. Ethanol derived from biomass feed stock which is one of the modern forms of biomass energy has the potential to be a sustainable transportation fuel as well as a fuel oxygenated that can replace gasoline [7]. The gradual increase in cell densities of the 3 substrates from the day one to the day seven of the fermentation periods suggested that substantially more carbon was utilized for ethanol production instead of cell production and this due to the ability of yeast $S$. cerevisiae to ferment the sugar to ethanol (Table I). The amount of biomass present in the substrates is directly proportional to quantity of ethanol production. Hence the pineapple peel which had the highest biomass production had the highest ethanol yield. This suggests that the favourable region for bio-ethanol industrial production should have surplus biomass that would not affect food security.

The susceptibility of sugars obtained after hydrolysis of the substrates by $A$. niger to the fermentation activity of $S$. cerevisae is significantly depended on the composition of sugar (Fig. 1). This is because various mixture of hexoses (e.g. glucose, mannose) and pentoses (e.g. xylose, arabinose) are released from the hydrolysis of lignocellulosic materials [14]. The fermentation process is significantly dependent on the effectiveness of sugar transporters of $S$. cerevisiae cells on translocating different sugars across the cell membrane (Fig. 1). Sugar transporters are membrane bound proteins that take up sugars from the environment and deliver them to the metabolic pathways insides cells. The result of this study agrees with the report of [7] that stated that most substrates are utilized for ethanol production in co-culture fermentation (Fig 2). No other sustainable option for the production of liquid fuels can match ethanol from lignocellulosic biomass with respect to its dramatic environmental, economic, and infrastructure advantages [2].

Conclusively, the present work has clearly shown that simultaneous saccharification and fermentation of waste materials from banana, plantain and pineapple to ethanol by a mixture of starch digesting fungus $A$. niger and non starch digesting sugar fermenter ( $S$. cerevisiae) is feasible. Simultaneous saccharification and fermentation has been found to effectively remove glucose, which is an inhibitor to cellulase activity, thus increasing the yield and rate of cellulose hydrolysis. It is interesting to note that even though ethanol is produce from renewable resource, economic factors such as land availability, labour, taxation, utilities, crop processing costs and transportation are to be put into consideration otherwise there will be no profit for its production.

\section{ACKNOWLEDGMENT}

We wish to thank the Department of Plant Science and Technology, Department of Chemistry and the Department of Biochemistry all of University of Jos, Nigeria for providing the chemicals and materials we used during the course of this work.

\section{REFERENCES}

[1] D. Pimentel and T. W. Patzek, "Ethanol Production Using Corn Switch grass and wood; Biodiesel Production using Soybean and sunflower," Natural Resources Research, vol. 14. no. 1, pp. 65-76., 2005.

[2] P. Chand and L. R. Venkateswar, "Thermotolerant yeasts for Bio-ethanol Production using Lignocellulosic substrates," Yeast 
Biotechnology: Diversity and Applications, vol. 111, pp. 551-588, 2009.

[3] S. C. Park and J. Barratti, "Kinetics of sugar beet molasses fermentation by Z. mobilis," J. of Biotech. and Bioeng. vol. 38, pp. 304, 1995.

[4] S. Joshi, S. R. Dhopeshwarker, U. Jadav, R. Jadav, L. D'souza, and D. Jayaprakash, "Continuous Ethanol Production by Fermentation of Waste Banana Peels Using Flocculating Yeast," Indian J. of Chem. Tech, vol. 40, pp.325, 2001.

[5] Z. S. Kadar, S. O. Szengyel, and K. Reckey, "Simultaneous Saccharification and Fermentation of Industrial Waste for the Production of Ethanol," J. of Industrial Crops and Products, vol. 20, no. 1, pp. 103-110, 2004.

[6] A. W. Ashiru, "Production of Ethanol from Molasses and Corn Cobs Using Yeast and A Mould," The Book of Abstract of the $29^{\text {th }}$ Annual Conference and General Meeting (Abeokuta, 2009) on Microbes As Agents of Sustainable Development Organized by Nigerian Society for Microbiology (NSM) University of Agriculture, Abeokuta, from 6-10 November, pp. 22, 2005

[7] S. O. Jimoh, S. A Ado, and J. B. Ameh, "Simultaneous Saccharification and Fermentation of Yam peel to Ethanol by Co-culture of Aspergillus niger and Saccharomyces cerevisae," Biol. and J. for the Tropics, vol. 6, no. 1, pp. 96-100, 2009.

[8] A. Omemu, M. I. Akpan, M. O. Bankole, and V. Teniola, "Hydrolysis of Raw Tuber Starches by Amylase of Aspergillus niger AMO7 Isolated from the Soil," African J. of Biotechnol, vol. 4, pp. 19-25, 2005.

[9] P. Susan, "Fermentation in the yeast Saccharomyces cerevisiae," Science Journal, vol. 1, pp. 8-12, 2010.

[10] A. V. Gusakov, A. P. Sinitsyn, J. A. Manenkova, and O. V. Prostas, "Enzymatic Saccharification of Industrial and Agricultural
Lignocellulosic wastes," Applied Biochemistry and Biotechnology, vol. 34 , pp. 65,1992

[11] SECO. (2006). State Energy Conservation Office. [Online]. Available: http://A:/Ethanol $\% 20$ production $\%$, no. 20 Ethanol Production in Texas in $20 \%$ Texas.htm.

[12] M. M. Abouzeid and A. Reddy, "Direct Fermentation of Potato Starch to Ethanol by Co-Culture of Aspergillus niger and Saccharomyces cerevisiae," J. of Appl. Microbiol. vol. 52. pp. 1055-1059, 1986.

[13] B. A. Amadi, E. N. Agomuo, and C. O. Ibegbulan, Research Methods in Biochemistry, Supreme Publishers, Owerri, Nigeria, pp. 93-99, 2004.

[14] Y. Sun and J. Cheng, "Hydrolysis of Lignocellulosic Material from Ethanol Production: A review," Biores. Technol, vol. 83, pp. 1-11, 2002

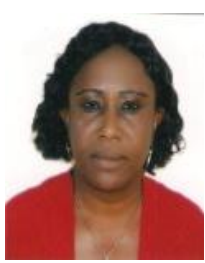

J. Itelima was born on 31, Januray, 1962 in Plateau State, Nigeria. She went to BSc (HONS) Botany in 1988, University of Jos, Nigeria. She applied her MSc Microbiology and Plant Pathology in 1993 in the University of Jos, Nigeria. Her major field of study is applied microbiology and plant pathology. Her current research interest include Bio-fuel, Bio-Fertilizer and Infectious microorganisms, Previous research interest: Research on Medicinal plants Current Job location: Department of Plant Science and Technology, Faculty of Natural Science, University of Jos, Nigeria. 